\title{
Ambient Air Pollution and Risk for Ischemic Stroke and Transient Ischemic Attack
}

\author{
Lynda D. Lisabeth, PhD, ${ }^{1,2}$ James D. Escobar, MPH, ${ }^{1}$ J. Timothy Dvonch, PhD, ${ }^{3}$ Brisa N. Sánchez, PhD, ${ }^{4}$ \\ Jennifer J. Majersik, MD, ${ }^{2}$ Devin L. Brown, MD, ${ }^{2}$ Melinda A. Smith, DrPH, ${ }^{2}$ \\ and Lewis B. Morgenstern, $\mathrm{MD}^{1,2}$
}

\begin{abstract}
Objective: Data on the association between air pollution and cerebrovascular disease in the United States are limited. The objective of this study was to investigate the association between short-term exposure to ambient air pollution and risk for ischemic cerebrovascular events in a US community.

Methods: Daily counts of ischemic strokes/transient ischemic attacks (TIAs) (2001-2005) were obtained from the populationbased Brain Attack Surveillance in Corpus Christi (BASIC) Project. Daily particulate matter less than $2.5 \mu \mathrm{m}$ in diameter $\left(\mathrm{PM}_{2.5}\right)$, ozone $\left(\mathrm{O}_{3}\right)$, and meteorological data were obtained from Texas Commission on Environmental Quality. To examine the association between $\mathrm{PM}_{2.5}$ and stroke/TIA risk, we used Poisson regression. Separate models included same-day $\mathrm{PM}_{2.5}$, $\mathrm{PM}_{2.5}$ lagged 1 to 5 days, and an averaged lag effect. All models were adjusted for temperature, day of week, and temporal trends in stroke/TIA. The effects of $\mathrm{O}_{3}$ were also investigated.

Results: Median $\mathrm{PM}_{2.5}$ was $7.0 \mu \mathrm{g} / \mathrm{m}^{3}$ (interquartile range, $4.8-10.0 \mu \mathrm{g} / \mathrm{m}^{3}$ ). There were borderline significant associations between same-day (relative risk [RR], 1.03; 95\% confidence interval [CI], 0.99-1.07 for an interquartile range increase in $\mathrm{PM}_{2.5}$ ) and previous-day (RR, 1.03; 95\% CI, 1.00-1.07) $\mathrm{PM}_{2.5}$ and stroke/TIA risk. These associations were independent of $\mathrm{O}_{3}$, which demonstrated similar associations with stroke/TIA risk (same-day RR, 1.02; 95\% CI, 0.97-1.08; previous-day RR, 1.04; 95\% CI, 0.99-1.09).

Interpretation: We observed associations between recent $\mathrm{PM}_{2.5}$ and $\mathrm{O}_{3}$ exposure and ischemic stroke/TIA risk even in this community with relatively low pollutant levels. This study provides data on environmental exposures and stroke risk in the United States, and suggests future research on ambient air pollution and stroke is warranted.
\end{abstract}

Ann Neurol 2008;64:53-59

Air pollution is linked to cardiovascular disease in general $^{1-6}$ and cardiac disease specifically. ${ }^{1,7-13}$ Data on the association between air pollution and stroke are more limited, although the underlying biological mechanisms linking air pollution to ischemic heart disease and cerebrovascular disease may be similar. Most of the evidence linking air pollution and stroke is from time-series analyses relating daily air pollution levels to daily counts of stroke deaths obtained from vital statistics or similar data sources. ${ }^{2,14-20}$ Studies have been conducted outside of the United States, ${ }^{14-17,19,20}$ with most demonstrating positive associations with one or more air pollutants. An association between air pollution and stroke mortality has also been noted in certain areas of the United States. ${ }^{4}$

To date, research on air pollution and incident stroke has primarily relied on routinely collected data sources, such as discharge diagnoses, to identify

From the ${ }^{1}$ Department of Epidemiology, University of Michigan School of Public Health; ${ }^{2}$ Stroke Program, University of Michigan Medical School; ${ }^{3}$ Department of Environmental Health Sciences, University of Michigan School of Public Health; and ${ }^{4}$ Department of Biostatistics, University of Michigan School of Public Health, Ann Arbor, MI.

Received Sep 21, 2007, and in revised form Feb 14, 2008. Accepted for publication Mar 14, 2008. strokes. ${ }^{19,21-25}$ In the United Kingdom, Canada, and China, stroke admissions have been shown to be associated with greater levels of air pollution. ${ }^{19,22,24,25}$ US studies of Medicare claims data and other billing data have also demonstrated associations between air pollution levels and hospital admissions for total cerebrovascular disease and ischemic stroke specifically. ${ }^{21,23,26} \mathrm{~A}$ recent analysis from the Dijon Stroke Register in France found an association between air pollution levels and ischemic stroke risk using population-based data. ${ }^{27}$ Data considering the relation between air pollution and incident stroke risk from population-based stroke studies in the United States are not available.

Although several air pollutants have been studied for their links to stroke and stroke mortality, including carbon monoxide, sulfur dioxide, nitrogen dioxide, and ozone, fine particulate matter $\left(\mathrm{PM}_{2.5}\right)$ has emerged as a pollutant of interest. $\mathrm{PM}_{2.5}$ is composed of particles

Published online May 28, 2008, in Wiley InterScience (www.interscience.wiley.com). DOI: 10.1002/ana.21403

Address correspondence to Dr Lisabeth, Department of Epidemiology, University of Michigan School of Public Health, 109 S. Observatory, Room 4641, Ann Arbor, MI 48109-2029.

E-mail: llisabet@umich.edu 
measuring less than $2.5 \mu \mathrm{m}$ in aerodynamic diameter in contrast with $\mathrm{PM}_{10}$, which is composed of larger particles measuring less than $10 \mu \mathrm{m}$, the majority of which are less than $2.5 \mu \mathrm{m} . \mathrm{PM}_{2.5}$, because of its smaller size and chemical activity, can penetrate the small airways and alveoli of the lung and enter the blood circulation. ${ }^{28}$ Exact biological mechanisms by which recent $\mathrm{PM}_{2.5}$ exposure may increase risk for acute cerebrovascular events are not known, but possible mechanisms include acute arterial vasoconstriction, ${ }^{29}$ acute increases in blood pressure, ${ }^{30}$ and acute increases in plasma viscosity. ${ }^{31}$

Ambient $\mathrm{PM}_{2.5}$ is a complex mixture and is composed not only of primary emissions from stationary and distributed sources, but also of secondary aerosol formed via atmospheric transformation. The production of fuels from crude oil is an example of a combustion process yielding primary emissions of fine particulate matter. Areas with a large petroleum and petrochemical industry presence provide an opportunity to study the health effects of $\mathrm{PM}_{2.5}$. Southeast Texas is home to several large oil refineries. The objective of this study was to investigate the association between short-term exposure to ambient $\mathrm{PM}_{2.5}$ and risk for ischemic cerebrovascular events in a southeast Texas community with a heavy fossil fuel industry presence using data from a population-based stroke surveillance study to capture stroke events.

\section{Subjects and Methods}

\section{Ischemic Stroke and Transient Ischemic Attack Case Identification}

Ischemic strokes and transient ischemic attacks (TIAs) were identified from the Brain Attack Surveillance in Corpus Christi Project (BASIC). BASIC is a population-based stroke surveillance project designed to capture all strokes in Nueces County, Texas, a geographically isolated, urban, biethnic community in southeast Texas. Nueces County has a population of roughly 310,000 that is more than half Mexican Americans. Nueces County serves as the regional referral medical center for southeast Texas and is approximately 150 miles from Houston and San Antonio. BASIC methodology has been described in detail elsewhere. ${ }^{32}$ In brief, between January 1, 2001, and December 31, 2005, trained abstractors, using validated screening procedures, identified ischemic stroke and TIA cases through active and passive surveillance of emergency department logs, hospital admissions records, and discharge diagnosis codes. Using published criteria, ${ }^{33}$ study neurologists blinded to age and ethnicity validated cases as ischemic stroke or TIA using source documentation. TIAs were included because of the similar underlying pathophysiology of TIAs and ischemic strokes; intracerebral hemorrhage cases were excluded because the pathophysiology differs from ischemic events. Individuals younger than 45 years, non-Nueces County residents, and those with traumatic strokes were excluded. The BASIC project was approved by the University of Michigan Institutional Review Board and each of the Nueces County hospitals.

\section{Air Pollutant/Meteorological Data}

Nueces County, Texas, is located on the Gulf Coast and is home to a large petroleum and petrochemical industry. Several refineries and chemical plants are located within close proximity to the 1,500 oil wells located in this region. Nineteen facilities in Nueces County were involved in the production/manufacturing of chemicals/petrochemicals in the years 1997 to 2002, as identified by the following Standard Industrial Classification industry codes: 1311 Operation of oil and gas field properties (4); 1321 Production of liquid hydrocarbons from oil and gas fields (3); 2819 Manufacturing industrial inorganic chemicals (1); 2869 Manufacturing industrial organic chemicals (3); 2911 Production of gasoline, kerosene, distillate fuel oils, residual fuel oils, and lubricants (7); and 9711 Armed forces establishment (1). ${ }^{34}$ There were 20 additional air pollutant emission point sources identified in the county. These facilities belonged to various industries including hardwood/plywood (1), paint (1), warehousing and storage (1), marine cargo handling (4), electrical (5) and natural gas services (3), refuse (1), chemicals (1), and petroleum stations (3).

Historical air pollutant and meteorological data for years 2001 to 2005 were obtained from the Texas Commission on Environmental Quality's Monitoring Operations Texas Historical Environmental Records (MOTHER) database. ${ }^{35}$ Six air-quality monitors are located within the city of Corpus Christi, Texas. Data on $\mathrm{PM}_{2.5}$ were available from one monitor, Corpus Christi West C4, which is geographically centered within the urban population. $\mathrm{PM}_{2.5}$ was measured in micrograms per cubic meter $\left(\mu \mathrm{g} / \mathrm{m}^{3}\right)$ and summarized as the hourly average per 24-hour time period. Of the 1,826 days in the study period, there were missing $\mathrm{PM}_{2.5}$ values for 12 days $(0.7 \%)$. One day with unusually high average $(64.4 \mu \mathrm{g} /$ $\left.\mathrm{m}^{3}\right)$ and peak $\mathrm{PM}_{2.5}\left(771.3 \mu \mathrm{g} / \mathrm{m}^{3}\right)$ measurements was excluded. Data on ozone $\left(\mathrm{O}_{3}\right)$ were obtained from the same monitor. $\mathrm{O}_{3}$ was measured in parts per billion and summarized as the hourly average per 24-hour time period. Ozone data were missing for 3 days. Ambient temperature was measured in degrees Celsius and summarized as the average peak hourly temperature per 24-hour time period. There were 35 days for which temperature data were not available (1.9\%). Wind direction and wind speed $(\mathrm{m} / \mathrm{sec})$ were also obtained, and wind rose analyses were conducted using WRPLOT View version 5.3.0.

The 39 air pollutant point emission sources were geocoded into Geographic Information System (GIS) using their latitude/longitude coordinate data. Figure 1 shows the criteria air pollutant point sources and the air-quality monitor in relation to place of residence of stroke/TIA cases. Analysis of the frequency of occurrence of winds in each of the specified wind direction sectors and wind speed classes for the Corpus Christi West C4 monitor for 2001 to 2005 demonstrated that the predominant winds were from the southeast. As shown in Figure 1, this predominant wind flow placed the monitor, and the majority of stroke/TIA cases, upwind of the local industrial facilities.

\section{Statistical Methods}

Stroke/TIA counts, air pollution, and temperature data were examined individually with descriptive statistics and time- 


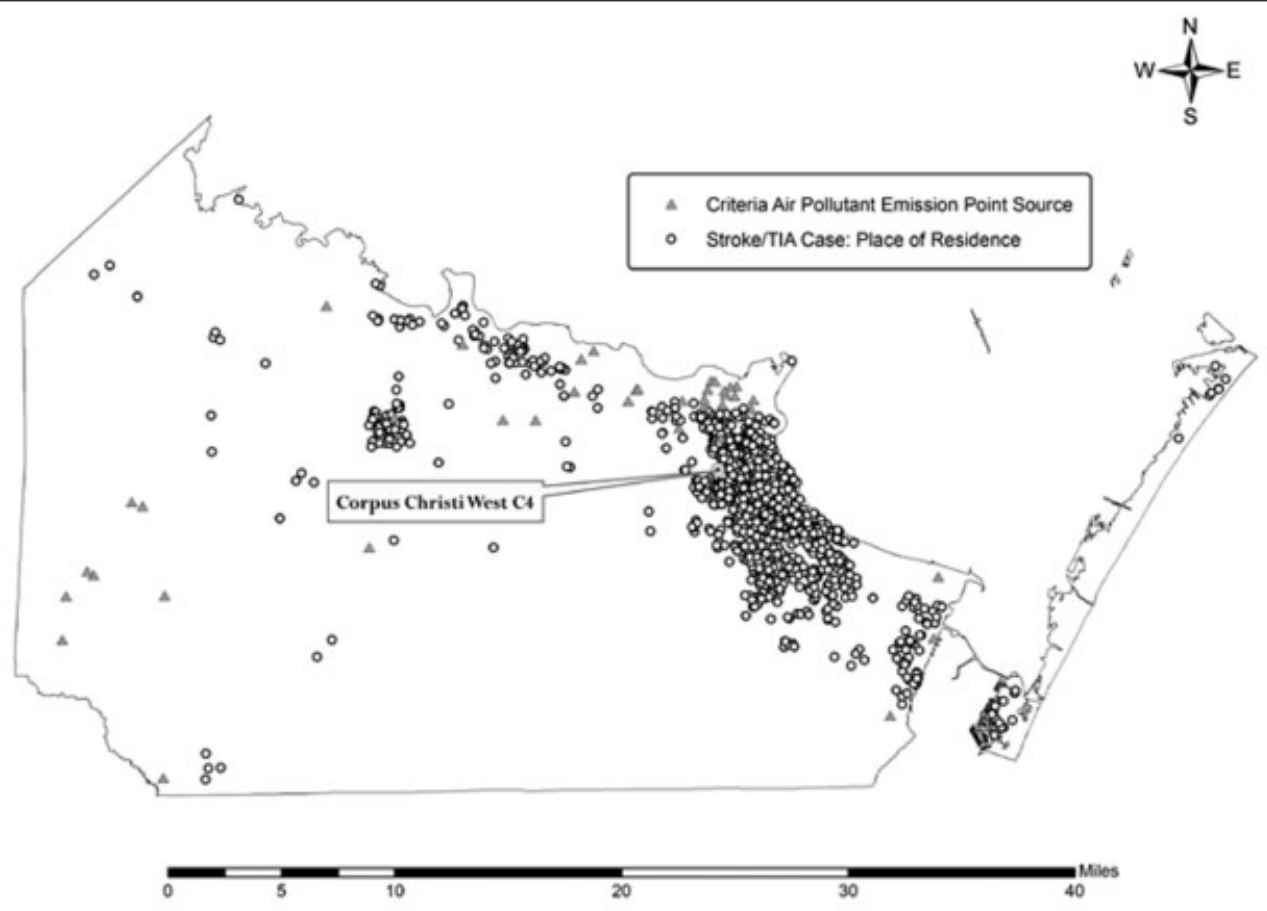

Fig 1. Air pollutant point emission sources in Nueces County, Texas. Triangles represent criteria air pollutant emission point source; circles represent stroke/transient ischemic attack case: place of residence.

series plots. To examine the association between $\mathrm{PM}_{2.5}$ and stroke/TIA risk, we used Poisson regression models. A semiparametric model was fit with daily stroke/TIA counts as the dependent variable. Parametric effects included same day (midnight to midnight on day of stroke/TIA) $\mathrm{PM}_{2.5}$ modeled as a continuous covariate and day of the week modeled as indicator variables with Sunday as the referent. Time in days was modeled using a natural cubic spline with three degrees of freedom to account for temporal trends in stroke/ TIA events over the study period; we opted for a small number of degrees of freedom because strong seasonal trends in the number of events were not found. Same-day average peak hourly temperature was modeled using a natural cubic spline with three degrees of freedom to account for the potential confounding effects of temperature. In additional models, $\mathrm{PM}_{2.5}$ was separately modeled as lagged variables up to 5 days before the date of stroke/TIA as the effects of $\mathrm{PM}_{2.5}$ on stroke/TIA may be delayed. For example, the lag 1 model represented $\mathrm{PM}_{2.5}$ levels for the 24 hours preceding the day of the stroke/TIA. Finally, an unconstrained distributed lag Poisson regression model was used to estimate the marginal effect on stroke/TIA risk associated with a unit increase in a 5-day weighted average of $\mathrm{PM}_{2.5}{ }^{36}$ This marginal effect was calculated by averaging coefficients of $\mathrm{PM}_{2.5}$ lags 0 to 5 after simultaneously including them in a single regression model. An advantage to the unconstrained distributed lag model is that it makes no assumptions about the functional form of the lag structure in estimating the marginal association of a unit increase in the weighted average of pollution and stroke rates.

In addition, we explored the potential confounding effects of $\mathrm{O}_{3}$ on the $\mathrm{PM}_{2.5}$ and stroke/TIA association given $\mathrm{O}_{3}$ has been linked to stroke. ${ }^{27}$ This was done by first considering the independent association between $\mathrm{O}_{3}$ and stroke/TIA in single-pollutant models. $\mathrm{O}_{3}$ was then added to the $\mathrm{PM}_{2.5}$ models (two-pollutant models) to determine the degree to which $\mathrm{O}_{3}$ confounded the $\mathrm{PM}_{2.5}$ and stroke/TIA association. Finally, we considered possible effect modification between season and $\mathrm{PM}_{2.5}$ on stroke/TIA risk given evidence that air pollution and temperature may have synergistic effects on health outcomes. ${ }^{17,22,37}$ Based on visual inspection of temperature data over the study time period, season was defined as summer (June through September) versus nonsummer (all other months). Effect modification was assessed by including an interaction term for $\mathrm{PM}_{2.5}$ and season in the singlepollutant $\mathrm{PM}_{2.5}$ models. To limit the number of models considered, we limited investigation of confounding and effect modification to models of same-day and previous-day $\mathrm{PM}_{2.5}$. All models were adjusted for day of the week, temperature, and temporal trends as described earlier.

The Poisson regression models were estimated without the use of an offset term, reflecting the assumption that the population at risk was relatively constant over the study period. To test this assumption, we conducted a sensitivity analysis using yearly intercensus population estimates as the offset term. The offset term was the estimated (log-transformed) population 45 years and older for Nueces County for a given year. The effects of $\mathrm{PM}_{2.5}$ were summarized as relative risk (RR) or percentage change for an interquartile range (IQR) increase in $\mathrm{PM}_{2.5}$ levels, and robust standard errors were used to compute confidence intervals for the effect estimates. ${ }^{38}$ All models were run in S-plus 7.0 for Windows, using the $\operatorname{glm}()$ function with stringent convergence criteria (data analyzed by L.D.L., B.N.S., and D.L.B.). 


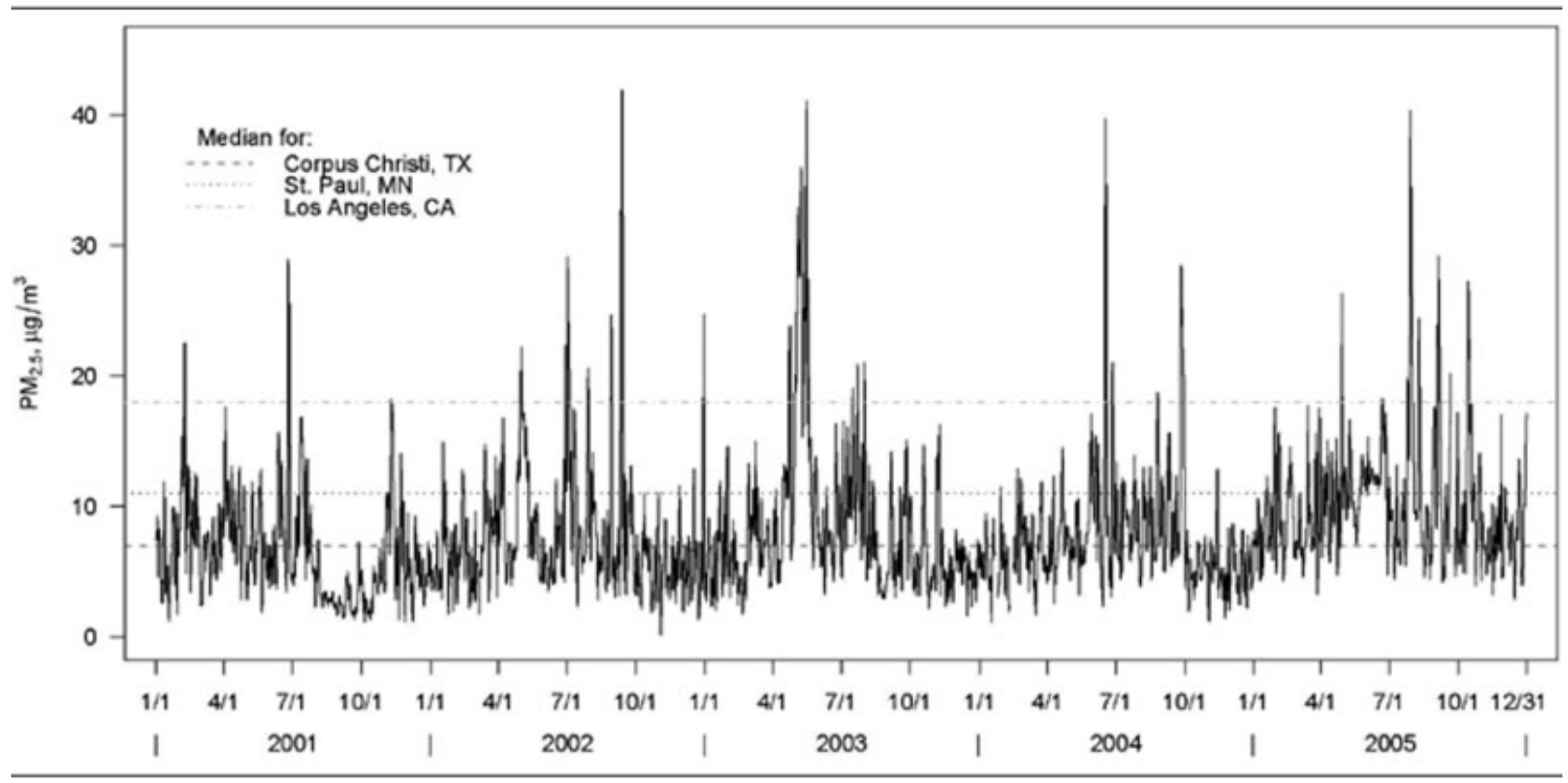

Fig 2. Daily and median level of particulate matter less than $2.5 \mu \mathrm{m}$ in diameter $\left(P M_{2.5}\right)$ over the study time period (2001-2005) with median $P M_{2.5}$ levels for two referent US cities.

\section{Results}

There were 3,508 stroke/TIAs (2,350 ischemic strokes [67.0\%] and 1,158 TIAs [33.0\%]) during the study time period. Median age of the stroke/TIA cases was 72 years (IQR, 62-81 years). Fifty-four percent of the cases were women $(\mathrm{n}=1,887)$. Fifty percent of the cases were Mexican American, 44\% non-Hispanic white, 5\% African American, and 1\% were other or undetermined race/ethnicity. Median number of stroke/TIAs per day was two (IQR, 1-3). For 287 $(15.7 \%)$ of the 1,826 days, there were no stroke/TIAs.

Median $\mathrm{PM}_{2.5}$ during the study time period was $7.0 \mu \mathrm{g} / \mathrm{m}^{3}$ (IQR, 4.8-10.0), which is well below the US Environmental Protection Agency National Ambient Air Quality Standard of $15 \mu \mathrm{g} / \mathrm{m}^{3}$ for annual $\mathrm{PM}_{2.5}$. Figure 2 displays daily levels and median level of $\mathrm{PM}_{2.5}$ over the study time period, with median levels for two other US cities included for reference. ${ }^{39}$ Median temperature during the study time period was $27.1^{\circ} \mathrm{C}$ (IQR, 22.4-30.9).

Figure 3 displays percentage change in stroke/TIA risk associated with an $\operatorname{IQR}\left(5.1 \mu \mathrm{g} / \mathrm{m}^{3}\right)$ increase in $\mathrm{PM}_{2.5}$. There were borderline significant associations between same-day (RR, 1.03; 95\% CI, 0.99-1.07 for an IQR increase in $\mathrm{PM}_{2.5}$ ) and previous-day ( $\mathrm{RR}$, 1.03; 95\% CI, 1.00-1.07) $\mathrm{PM}_{2.5}$ exposure and stroke/ TIA risk. $\mathrm{PM}_{2.5}$, modeled as lagged variables 2 to 5 days before the stroke/TIA, was not significant. $\mathrm{PM}_{2.5}$ modeled as an averaged lag effect was also not significant. Parameter estimates were minimally impacted ( $<1 \%$ change) by inclusion of an offset term reflecting an average annual increase in the population of roughly $2 \%$ during the study time period.

Median $\mathrm{O}_{3}$ was 25.6 parts per billion (IQR, 18.133.8). Results of the analysis including $\mathrm{O}_{3}$ are included in the Table. The associations between same-day (RR, 1.02; 95\% CI, 0.97-1.08) and previous-day (RR, 1.04; 95\% CI, 0.99-1.09) $\mathrm{O}_{3}$ exposure and stroke/TIA risk were similar in magnitude to $\mathrm{PM}_{2.5}$. When $\mathrm{O}_{3}$ was

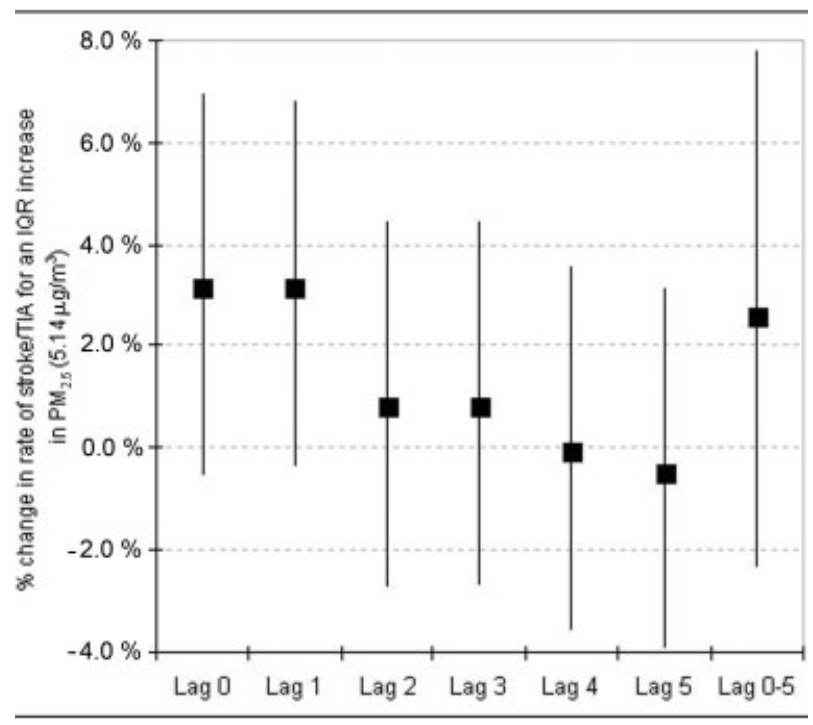

Fig 3. Percentage change in strokeltransient ischemic attack (TIA) risk associated with an interquartile range (IQR; $\left.5.1 \mu \mathrm{g} / \mathrm{m}^{3}\right)$ increase in particulate matter less than $2.5 \mu \mathrm{m}$ in diameter $\left(P M_{2.5}\right)$. 


\begin{tabular}{|c|c|c|c|c|c|}
\hline \multirow[t]{2}{*}{ Model } & \multirow[t]{2}{*}{ Pollutant } & \multicolumn{2}{|c|}{ Same-Day Models } & \multicolumn{2}{|c|}{ Previous-Day Models } \\
\hline & & $\mathbf{R R}$ & $95 \%$ CI & $\mathbf{R R}$ & 95\% CI \\
\hline \multirow[t]{2}{*}{ Single-pollutant models } & $\mathrm{PM}_{2.5}$ & 1.03 & $0.99-1.07$ & 1.03 & $1.00-1.07$ \\
\hline & $\mathrm{O}_{3}$ & 1.02 & $0.97-1.08$ & 1.04 & $0.99-1.09$ \\
\hline \multirow{2}{*}{ Two-pollutant models } & $\mathrm{PM}_{2.5}$ & 1.03 & $0.99-1.07$ & 1.03 & $0.99-1.06$ \\
\hline & $\mathrm{O}_{3}$ & 1.02 & $0.97-1.07$ & 1.03 & $0.98-1.09$ \\
\hline
\end{tabular}

added to the $\mathrm{PM}_{2.5}$ models, parameter estimates for $\mathrm{PM}_{2.5}$ were largely unchanged (same-day $\mathrm{PM}_{2.5}: \mathrm{RR}$, 1.03; 95\% CI, 0.99-1.07; previous-day $\mathrm{PM}_{2.5}$ : RR, 1.03; 95\% CI, 0.99-1.06). Season did not modify the association of $\mathrm{PM}_{2.5}$ on stroke/TIA risk ( same-day $p=$ 0.49 ; previous-day $p=0.55$ ).

\section{Discussion}

We observed borderline significant associations between same-day and previous-day $\mathrm{PM}_{2.5}$ exposures and ischemic stroke/TIA risk accounting for temperature, day of the week, and temporal trends in stroke/TIA events. These results were not confounded by $\mathrm{O}_{3}$, and the effects of $\mathrm{PM}_{2.5}$ on stroke/TIA risk did not differ based on season. Similar associations between same-day and previous-day $\mathrm{O}_{3}$ and stroke/TIA risk were also observed. These data contribute to the literature because there is currently a scarcity of data on the effect of environmental exposures on risk for stroke in the United States. The relation between $\mathrm{PM}_{2.5}$ and stroke/ TIA was observed in this US community with a heavy fossil fuel industry presence but with relatively low exposure to $\mathrm{PM}_{2.5}$ relative to other regions in the United States. ${ }^{39}$ This finding is consistent with previous research demonstrating an association between $\mathrm{PM}_{2.5}$ and stroke mortality even in a low air pollution area in Europe ${ }^{17}$ Although the magnitude of increased risk for stroke/TIA because of $\mathrm{PM}_{2.5}$ exposure $(3 \%$ per $5 \mu \mathrm{g} / \mathrm{m}^{3}$ increase in $\mathrm{PM}_{2.5}$ ) was relatively small, most of the public is exposed to ambient air pollution at the levels observed in this community or greater every day, suggesting a potentially large public health impact.

This is the first report linking $\mathrm{PM}_{2.5}$ to ischemic stroke/TIA in the United States using data from a population-based stroke surveillance study with active and passive surveillance methods and rigorous case validation procedures. Use of these methods to identify events ensures complete case capture of stroke/TIAs in comparison with passive surveillance alone, which has been used in the majority of studies to date but has also been shown to miss a considerable proportion of stroke/TIAs. ${ }^{32}$ Furthermore, the case ascertainment methods used eliminate the possibility of including events that are not stroke or TIA. Dominici and colleagues $^{21}$ report a roughly $1 \%$ change in hospital admissions for total cerebrovascular disease for a $10 \mu \mathrm{g} / \mathrm{m}^{3}$ increase in same-day $\mathrm{PM}_{2.5}$ levels. This study was conducted in 204 US counties with an average $\mathrm{PM}_{2.5}$ level considerably greater than this study $\left(13.4 \mu \mathrm{g} / \mathrm{m}^{3}\right)$. Wellenius and coauthors ${ }^{23}$ report a $1 \%$ change in hospital admissions for ischemic stroke but for a roughly $20 \mu \mathrm{g} / \mathrm{m}^{3}$ increase in same-day $\mathrm{PM}_{10}$ levels. Both studies report no association for air pollution levels measured 1 to 2 days before stroke admission. Our effect size was likely larger because of the different case ascertainment methods and inclusion of TIAs.

Several studies have considered total cerebrovascular disease or total stroke deaths, although the different stroke types are likely to be affected by air pollution through different biological mechanisms and may have different critical periods of exposure. Our findings support the hypothesis that recent exposure to $\mathrm{PM}_{2.5}$ may increase risk for acute ischemic cerebrovascular events specifically. Experimental evidence suggests that particulate air pollution is associated with acute artery vasoconstriction $^{29}$ and also with increases in plasma viscosity, ${ }^{31}$ processes that may enhance the potential for thrombosis, but this requires further study. We did not have data on ischemic stroke subtypes, but investigation into the associations between $\mathrm{PM}_{2.5}$ and ischemic stroke subtypes could shed light on the specific biological mechanisms linking $\mathrm{PM}_{2.5}$ and risk for ischemic stroke. Because of the high case fatality rates associated with intracerebral hemorrhage and the inconsistent findings about the effect of air pollution on this stroke type, ${ }^{22,23,25,27}$ additional studies on this topic are also warranted.

The US Environmental Protection Agency National Ambient Air Quality Standard for annual $\mathrm{PM}_{2.5}$ is $15 \mu \mathrm{g} / \mathrm{m}^{3}$, and the current National Ambient Air Quality Standard for 24-hour average $\mathrm{PM}_{2.5}$ is $65 \mu \mathrm{g} / \mathrm{m}^{3}$. In this community, the 99th percentile of the distribution of $\mathrm{PM}_{2.5}$ levels was well below the 24-hour standard at roughly $28 \mu \mathrm{g} / \mathrm{m}^{3}$ likely because of the coastal location 
of the community and prevailing wind patterns. Although our observed association between $\mathrm{PM}_{2.5}$ and stroke/TIA risk requires further study in additional regions in the United States with varying types of climates and possibly with alternative study designs, it does call into question current standards for fine particulate matter and whether these standards are sufficient to protect the public from stroke, the nation's third leading cause of death. Critical to this issue is the further study of the specific components of $\mathrm{PM}_{2.5}$, the geographic variability in $\mathrm{PM}_{2.5}$ chemical composition, and the pathways by which these components directly affect ischemic stroke/TIA risk. We did not have data on the specific composition of $\mathrm{PM}_{2.5}$ in this study population, although this could shed light on the observed association despite the low levels of $\mathrm{PM}_{2.5}$. Previous research suggests regional differences in the association between $\mathrm{PM}_{2.5}$ and stroke hospitalizations likely caused by differences in $\mathrm{PM}_{2.5}$ composition. ${ }^{21}$

Although the focus of this study was $\mathrm{PM}_{2.5}$, the observed borderline association between low levels of $\mathrm{O}_{3}$ and stroke/TIA risk suggests that ambient air pollution, in general, may affect stroke risk. Although some studies reviewing multiple pollutants within the same population have found similar associations with stroke end points across pollutants, ${ }^{14,15,23}$ this has not been a consistent finding. ${ }^{17,27}$ Most recently, investigators from the Dijon Stroke Register, a population-based stroke registry, reported on the association between short-term exposure to various air pollutants and ischemic stroke/TIA risk using a case-crossover approach. ${ }^{27}$ This study found a significant association between previous-day $\mathrm{O}_{3}$ and ischemic stroke/TIA risk but did not find associations for $\mathrm{PM}_{10}$, sulfur dioxide, nitrogen dioxide, or carbon monoxide. Additional studies are required to understand whether specific air pollutants and their constituents are particularly harmful for stroke or whether air pollution in general affects stroke risk.

\section{Limitations}

This was an ecological study and should be used primarily for hypothesis generation. Although the findings are intriguing, they should be replicated. Given the study findings, future work should focus on confirming that the observed association was not due to additional unmeasured variables. For example, we were unable to determine the possible confounding or interaction effects of sex and race/ethnicity on stroke/TIA risk because of the ecological design. If the findings are confirmed, the identification of any susceptible subgroups of people will be an important next step. Assessment of $\mathrm{PM}_{2.5}$ is subject to measurement error on various levels. Exposures were estimated from average $\mathrm{PM}_{2.5}$ measurements from a single monitor for the Corpus Christi area and may not accurately reflect $\mathrm{PM}_{2.5}$ levels across small geographic areas within the county. In addition, the measurement of $\mathrm{PM}_{2.5}$ from fixed monitors may be subject to error, although US Environmental Protection Agency standardized methods were used to collect the ambient $\mathrm{PM}_{2.5}$ data. Some research suggests that the effects of air pollution on mortality, stroke, and stroke outcomes are limited to or enhanced by warm weather perhaps because of greater exposure to outdoor air. ${ }^{17,22,37}$ Within our study, we did not find that season modified the effect of $\mathrm{PM}_{2.5}$ on stroke/TIA risk; however, this study was conducted in a coastal area with relatively high year-round temperatures and humidity, so the findings may not be generalizable to areas with varying climates. Our analysis focused primarily on $\mathrm{PM}_{2.5}$ given its plausible biological link to the cardiovascular system and adjusted for the confounding effects of $\mathrm{O}_{3}$; however, residual confounding by other pollutants is possible.

\section{Conclusion}

We observed an association between same-day and previous-day $\mathrm{PM}_{2.5}$ exposure and risk for ischemic stroke/TIA using data from a population-based stroke surveillance study in a US community with relatively low $\mathrm{PM}_{2.5}$ levels. This study contributes data on environmental exposures and stroke risk in the United States, and suggests that additional research on this topic is warranted.

This study was supported by the NIH (NINDS) (RO1 NS38916, B.M.S., M.A.S., L.B.M.).

We thank Drs M. Oneill and N. Ranjit for their advice on unconstrained distributed lag Poisson regression models.

\section{References}

1. Kunzli N, Jerrett M, Mack WJ, et al. Ambient air pollution and atherosclerosis in Los Angeles. Environ Health Perspect 2005;113:201-206.

2. Moolgavkar SH. Air pollution and daily mortality in three U.S. counties. Environ Health Perspect 2000;108:777-784.

3. Moolgavkar SH. Air pollution and hospital admissions for diseases of the circulatory system in three U.S. metropolitan areas. J Air Waste Manag Assoc 2000;50:1199-1206.

4. Samet JM, Dominici F, Curriero FC, et al. Fine particulate air pollution and mortality in 20 U.S. cities, 1987-1994. N Engl J Med 2000;343:1742-1749.

5. Schwartz J. Air pollution and hospital admissions for cardiovascular disease in Tucson. Epidemiology 1997;8:371-377.

6. Kelsall JE, Samet JM, Zeger SL, Xu J. Air pollution and mortality in Philadelphia, 1974-1988. Am J Epidemiol 1997;146: $750-762$.

7. Dockery DW, Luttmann-Gibson H, Rich DQ, et al. Particulate air pollution and nonfatal cardiac events. Part II. Association of air pollution with confirmed arrhythmias recorded by implanted defibrillators. Res Rep Health Eff Inst 2005:83-148.

8. Liao D, Duan Y, Whitsel EA, et al. Association of higher levels of ambient criteria pollutants with impaired cardiac autonomic control: a population-based study. Am J Epidemiol 2004;159: $768-777$. 
9. Peters A, Liu E, Verrier RL, et al. Air pollution and incidence of cardiac arrhythmia. Epidemiology 2000;11:11-17.

10. Peters A, Perz S, Doring A, et al. Increases in heart rate during an air pollution episode. Am J Epidemiol 1999;150: 1094-1098.

11. Peters A, von Klot S, Heier M, et al. Particulate air pollution and nonfatal cardiac events. Part I. Air pollution, personal activities, and onset of myocardial infarction in a case-crossover study. Res Rep Health Eff Inst 2005:1-82, 141-148.

12. Schwartz J, Dockery DW, Neas LM. Is daily mortality associated specifically with fine particles? J Air Waste Manag Assoc 1996;46:927-939.

13. von Klot S, Peters A, Aalto P, et al. Ambient air pollution is associated with increased risk of hospital cardiac readmissions of myocardial infarction survivors in five European cities. Circulation 2005;112:3073-3079.

14. Hong YC, Lee JT, Kim H, et al. Effects of air pollutants on acute stroke mortality. Environ Health Perspect 2002;110: 187-191.

15. Hong YC, Lee JT, Kim H, Kwon HJ. Air pollution: a new risk factor in ischemic stroke mortality. Stroke 2002;33:2165-2169.

16. Kan H, Jia J, Chen B. Acute stroke mortality and air pollution: new evidence from Shanghai, China. J Occup Health 2003;45: 321-323.

17. Kettunen J, Lanki T, Tiittanen P, et al. Associations of fine and ultrafine particulate air pollution with stroke mortality in an area of low air pollution levels. Stroke 2007;38:918-922.

18. Kim H, Kim Y, Hong YC. The lag-effect pattern in the relationship of particulate air pollution to daily mortality in Seoul, Korea. Int J Biometeorol 2003;48:25-30.

19. Maheswaran R, Haining RP, Brindley P, et al. Outdoor air pollution and stroke in Sheffield, United Kingdom: a small-area level geographical study. Stroke 2005;36:239-243.

20. Maheswaran R, Haining RP, Pearson T, et al. Outdoor NOx and stroke mortality: adjusting for small area level smoking prevalence using a Bayesian approach. Stat Methods Med Res 2006;15:499-516.

21. Dominici F, Peng RD, Bell ML, et al. Fine particulate air pollution and hospital admission for cardiovascular and respiratory diseases. Jama 2006;295:1127-1134.

22. Tsai SS, Goggins WB, Chiu HF, Yang CY. Evidence for an association between air pollution and daily stroke admissions in Kaohsiung, Taiwan. Stroke 2003;34:2612-2616.

23. Wellenius GA, Schwartz J, Mittleman MA. Air pollution and hospital admissions for ischemic and hemorrhagic stroke among Medicare beneficiaries. Stroke 2005;36:2549-2553.

24. Wordley J, Walters S, Ayres JG. Short term variations in hospital admissions and mortality and particulate air pollution. Occup Environ Med 1997;54:108-116.

25. Villeneuve PJ, Chen L, Stieb D, Rowe BH. Associations between outdoor air pollution and emergency department visits for stroke in Edmonton, Canada. Eur J Epidemiol 2006;21: $689-700$
26. Low RB, Bielory L, Qureshi AI, et al. The relation of stroke admissions to recent weather, airborne allergens, air pollution, seasons, upper respiratory infections, and asthma incidence, September 11, 2001, and day of the week. Stroke 2006;37: 951-957.

27. Henrotin JB, Besancenot JP, Bejot Y, Giroud M. Short-term effects of ozone air pollution on ischaemic stroke occurrence: a case-crossover analysis from a 10-year population-based study in Dijon, France. Occup Environ Med 2007;64:439-445.

28. Nemmar A, Hoet PH, Vanquickenborne B, et al. Passage of inhaled particles into the blood circulation in humans. Circulation 2002;105:411-414.

29. Brook RD, Brook JR, Urch B, et al. Inhalation of fine particulate air pollution and ozone causes acute arterial vasoconstriction in healthy adults. Circulation 2002;105:1534-1536.

30. Urch B, Silverman F, Corey P, et al. Acute blood pressure responses in healthy adults during controlled air pollution exposures. Environ Health Perspect 2005;113:1052-1055.

31. Peters A, Doring A, Wichmann HE, Koenig W. Increased plasma viscosity during an air pollution episode: a link to mortality? Lancet 1997;349:1582-1587.

32. Piriyawat P, Smajsova M, Smith MA, et al. Comparison of active and passive surveillance for cerebrovascular disease: The Brain Attack Surveillance in Corpus Christi (BASIC) Project. Am J Epidemiol 2002;156:1062-1069.

33. Asplund K, Tuomilehto J, Stegmayr B, et al. Diagnostic criteria and quality control of the registration of stroke events in the MONICA project. Acta Med Scand 1988;728:26-39.

34. Standard Industrial Classification (SIC) system search. Occupational Safety and Health Administration (OSHA), U.S. Department of Labor. Available at: http://www.osha.gov/pls/imis/ sicsearch.html. Accessed November 11, 2006.

35. Historical Air Pollutant and Weather Data. Monitoring Operations Texas Historical Environmental Records (MOTHER), Texas Commission on Environmental Quality (TCEQ). http:// www.tceq.state.tx.us/compliance/monitoring/air/monops/ historical_data.html. Accessed November 11, 2006.

36. Schwartz J. The distributed lag between air pollution and daily deaths. Epidemiology 2000;11:320-326.

37. Katsouyanni K, Pantazopoulou A, Touloumi G, et al. Evidence for interaction between air pollution and high temperature in the causation of excess mortality. Arch Environ Health 1993; 48:235-242.

38. Dominici F, McDermott A, Zeger SL, Samet JM. On the use of generalized additive models in time-series studies of air pollution and health. Am J Epidemiol 2002;156:193-203.

39. Diez Roux AV, Auchincloss AH, Astor B, et al. Recent exposure to particulate matter and C-reactive protein concentration in the multi-ethnic study of atherosclerosis. Am J Epidemiol 2006; 164:437-448 